\title{
Second Language Acquisition via Virtual Learning Platforms: A Case Study on Romanian Experiences
}

\author{
Lucia-Mihaela Grosu-Rădulescu' \& Veronica-Maria Stan ${ }^{2}$ \\ ${ }^{1}$ The Bucharest University of Economic Studies, Romania.ORCID: oooo-ooo1-8183-3263. \\ Email: grosulucia@gmail.com, \\ ${ }^{2}$ The Bucharest University of Economic Studies, Romania. \\ Email:stan.veronicao1@gmail.com
}

Received April 21, 2018; Revised August 01, 2018: Accepted August 29, 2018; Published November 03, 2018.

\begin{abstract}
Dwelling on the relationship between second language acquisition and independent study, the present article will analyze the relevance of foreign language learning online platforms. Our main assumption is that young adults are inclined to improve their foreign language skills by accessing virtual learning platforms as this experience is emphasizing their need to belong to online learning communities. This study begins with a critical approach of recent trends in learning/ teaching methods in the field of foreign languages. We will mention some successful blended learning strategies for the acquisition and assessment of foreign languages, but we will also pinpoint the limits of such methods. We will then provide a short overview of previous research in this domain conducted in Romania with a focus on the Bucharest University of Economic Studies' efforts to include an online component in its teaching activities.

Our subsequent analytic section will be constructed on data gathered through a survey conducted in 2016 with tertiary learners from different Romanian academic centers. We will show that by drawing the profile of the $21^{\text {st }}$ century foreign language online learner, we can make informed suggestions for updating foreign language teaching methods. Our main purpose is to predict fresh interactive techniques that could appeal more to students in our domain of interest. We will show that such up-to-date methods can improve not only students' results in foreign language learning but they can also provide an additional environment where students can make independent learning choices. We will also address the limits of our study and possible subsequent directions of research in order to gather more data that could supplement our initial findings.
\end{abstract}

Keywords: virtual learning platforms, foreign language learning, independent students

\section{Introduction}

Foreign language learning in the $21^{\text {st }}$ century is receiving more and more attention from researchers and practitioners alike. The expansion of the economic boundaries across the world, indeed the process of globalization has had an important impact on language learning and teaching. Historically speaking, foreign language learning in Romania has benefited from attention in curricula design, especially after the fall of communism in 1989. After Romania joined the EU in 2007 this preoccupation has become even more visible at the level of primary, secondary and tertiary education. The high number of student and staff mobility programmes, intensive language learning in high schools and universities, together with Romanian researchers'

(C) AesthetixMS 2018. This Open Access article is published under a Creative Commons Attribution Non-Commercial 4.0 International License (http://creativecommons.org/licenses/by-nc/4.0/), which permits non-commercial re-use, distribution, and reproduction in any medium, provided the original work is properly cited. For citation use the DOI. For commercial re-use, please contact editor@rupkatha.com. 
active involvement in the development and implementation of European Language selfassessment tools all point towards a prominent status of foreign language education in our country.

This ascending trend has also been accompanied by the rapid spread and development of technology and the Internet which have had a great impact on how people work and learn. It is the purpose of the present article to show that nowadays' foreign language teachers can (and must) capitalize on the richness of online-based language platforms in order to adapt their interactive methods to the present-day profile of the online learner. Nevertheless, we need not forget that there have also been recent concerns with how technologization has been deemed "[...] detrimental to young people's thinking and literacy, with the 21st-century ethos of rapid access to bits of information leading to fragmented experience, compromised ability to focus on other people, and lessened ability to think critically or argue logically" (Bauerlein, 2009 \& Carr, 2010 qtd. in Chun, Smith \& Kern 2016, p.65).

The initial assumption of our study is that young adults (university students) have a proclivity towards using online learning platforms in order to improve their foreign language skills. In 2016, David and Grosu-Rădulescu conducted a study at the Bucharest University of Economic Studies regarding students' motivation to learn foreign languages in the classroom environment as well as in the online space. The research showed that in order to achieve good results as well as a feeling of personal accomplishment students needed to consider themselves part of a learning community. As it will be shown in the subsequent part of this paper, our survey also tests the respondents' reasons for using online language learning platforms. In the conclusions we will compare the results of the two studies in search of similarities and differences.

\section{Online Learning/ Teaching}

In a recent article regarding perspectives on foreign language teaching, Collins and Munoz voice their concerns about the future of the traditional classroom teaching and learning. They raise an interesting question: "Are language teachers truly an endangered species, and has the language classroom become an obsolete learning environment?" (Collins \& Munoz, 2016, p.133). The authors of the present paper are inclined to think that at least for a while and at least in the case of Romanian education, language teaching will still take place within the walls of classrooms. However, taking into account (relatively) recent preoccupations of Romanian foreign language instructors with taking advantage of the richness of ICT tools and Internet-based applications and platforms, the trend seems to be towards (at least) an inclusion of technological aids in the language class.

According to Toth and Davin (2016), "highly effective pedagogy requires viewing language and language learning as both cognitive and social phenomena, and [...] teachers who seek to truly understand their responsibilities do not have the luxury of choosing one perspective over the other" (p. 149). If we consider this perspective and if we take into account the increasingly virtual characteristic of nowadays' students' social lives, teaching methods should be accordingly adapted to ensure effectiveness. Even as early as 1997, Firth and Wagner were advising that professors need "a significantly enhanced awareness of the contextual and interactional dimensions of language use" (p. 286). Our students' communication contexts have greatly changed and therefore teaching tools need to keep up with "the diversity of environments that support 
teaching and learning" (Collins \& Munoz, 2016, p.139) which are constantly "expanding the boundaries of space and time" (Trilling \& Fadel, 2009, p. 139).

What started as a practical necessity in order to cater to distance learners' needs has now become part of modern daily teaching tools. Online platforms of different shapes and functionalities have been implemented worldwide in order to support students' inclinations to rely on virtual means. Massive Open Online Courses (MOOCs) or Blended Learning Platforms are increasingly used by universities in Romania as well. However, only with the passing of time and after further research can we conclude on their success.

As David and Grosu-Rădulescu (2016) have previously shown, second language learning motivation appears to be still relying on face-to-face interaction mediated by teachers. Nevertheless, their article also points out the fact that, given the research data provided by different Romanian studies and also their own observations, students display a clear attraction to online-based tools. One such example is the Blended Learning platform (online.ase.ro) implemented by the Bucharest University of Economic Studies (BUES) in 2014. In an earlier study, Grosu-Rădulescu and David (2015) tested the degree of functionality of the platform as far as their English for Specific Purposes courses were concerned. Their conclusions revealed an interesting aspect regarding online behaviour: many of the undergraduate students expressed their lack of confidence in the platform when uploading their assignments (although students receive an immediate automatic reply for each upload activity) and therefore they also submitted their works directly to the professor's email. This scepticism in the capabilities of the online platform seems characteristic of younger students (first year undergraduates) and could be motivated by their lack of experience in the university environment and their eagerness to ensure good academic results.

\section{Survey and Data Analysis}

\subsection{Overall description of the survey}

The present research was prompted by the hypothesis that when driven by personal goals and when they do not experience the pressure of traditional classroom language teaching/ learning (which is always assessed with grades that impact on students' overall university performance) students find enough motivation to focus on individual language study via language learning platforms.

In order to test our assumption, we have devised an online questionnaire with 18 questions (see Appendix) directed at undergraduate and graduate students from different universities in Romania. The questionnaire was disseminated on Facebook mainly to pages belonging to student organizations and it was available online for two weeks in November 2016. Since the majority of respondents were BUES students we have also included an awareness question related to the institutional Blended Learning platform. The four websites we have chosen in the list of online language learning platforms were some of the most prominent, namely Duolingo, Linguotica, Babbel and Memrise.

The questionnaire also included additional questions (about level of education, gender, city/county of origin) in order to allow us to draw the profile of the users of language platforms. In terms of previous language education, we have provided a list of seven foreign languages to be selected by respondents with the possibility to add another one if missing from the list. 
Question 12 tests whether respondents have chosen to use virtual language learning platforms to improve their language skills or to learn a new language starting from the very beginning. The following question enquires about the language learning advantages offered by the online platforms, ranging from listening to correct pronunciation of words, to the overall time/ space accessibility of learning online and the attractiveness of such a learning experience. The respondents also had the opportunity to fill in other such advantages. To this we added a further question related to the initial reason to start using an online platform to either improve language knowledge or begin learning a new language altogether. The respondents were asked to choose if they valued the fact that online individual study offers as much time as necessary to achieve learning goals, or if they were attracted by the perspective of learning at a professional level or if they appreciated more the possibility of learning on their own.

The final questions, 16 to 18 , assess the amount of time dedicated to online study and the level of proficiency achieved by the respondents as well as the effectiveness of the chosen language learning platform.

\subsection{Data Analysis}

The respondents' profiles consist of students from various universities, predominantly from the Bucharest University of Economic Studies, but also from the University of Bucharest and "BabesBolyai" University in Cluj, Romania. Furthermore, $8 \%$ of the respondents belong to other universities in Bucharest and universities in other Romanian counties, such as Sibiu and Timișoara. The questionnaire participants are undergraduates and graduates, third year undergraduate students representing the biggest group. The age of the respondents is between 18 and 24 years old, with $70 \%$ of the total respondents being volunteers in student organizations and the rest being involved in various extra-curricular activities.

The questionnaire gathered answers from a pool of 101 people, female learners being predominant (almost $80 \%$ of respondents). The majority originate from other counties than Bucharest, with almost $70 \%$ of the respondents having their city of origin outside of Bucharest.

In the process of data analysis, we discovered that the most studied foreign languages by the respondents were English, French, German and Spanish. This result led us to the assumption that learners are more inclined to study languages which are widely used in international communication, rather than to learn rare languages.

Interesting findings of the survey were generated by Question 8 related to the awareness of the Blended Learning platform implemented by the Bucharest University of Economic Studies. The results were very relevant to the university, if we are to take into account the fact that just a few years have passed since the launch of this Blended Learning platform and that all students of this university are aware of its existence, even if they do not use it at its full potential. However, even if the majority of the respondents were aware of the platform's existence, no respondent used this blended learning platform in order to learn foreign languages. 


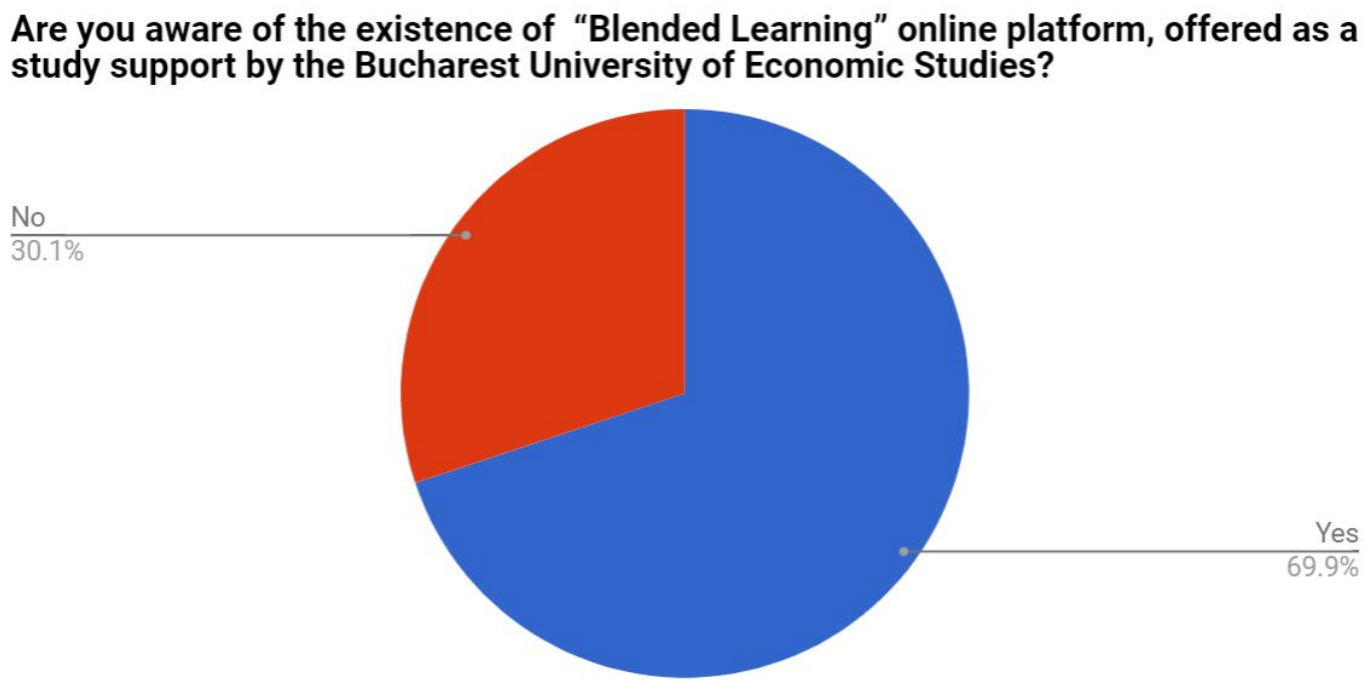

Fig. 1. Students' awareness of the institutional Blended Learning platform.

With regard to the student's attraction to online based tools and their desire to learn foreign languages, we aimed to find out if they have ever used online language learning platforms before. The response was positive from more than $58 \%$ of the respondents. This percentage indicates that Romanian students are eager to learn foreign languages, and more than half of the respondents tried to study online at least one language.

We also aimed to identify which online language learning platform was preferred by the respondents and which online platform they have used so far. The most used online language learning platform was Duolingo, mainly because of its popularity among Romanians. The online language learning platforms were considered easy to use (Question 11), which is not surprising given the fact that the respondents were mostly students who were accustomed to technology and the online environment. Furthermore, the results regarding this particular question revealed the fact that Duolingo is designed in a way that makes it very intuitive, therefore, user-friendly.

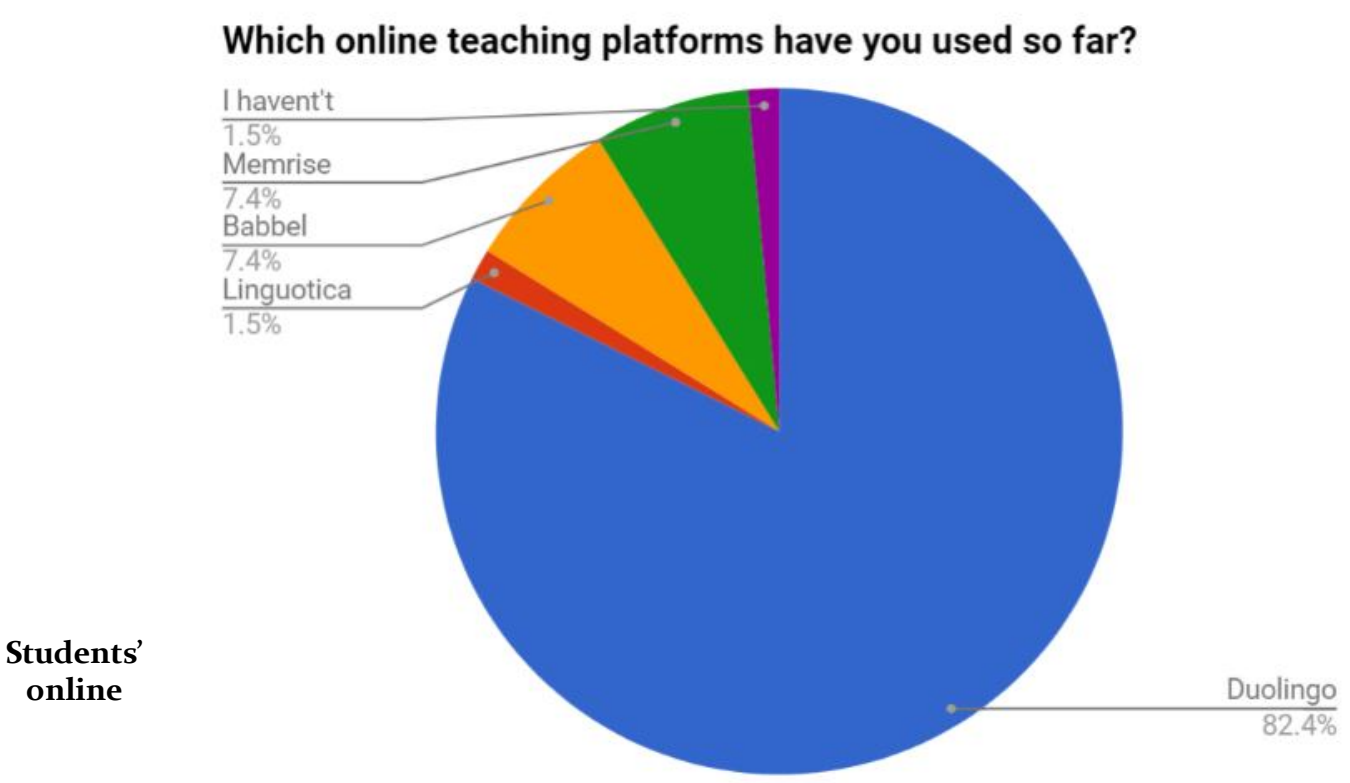

Fig. 2. preference of platforms 
An interesting result yielded was that students have started to choose learning a new language from zero through online language learning platforms, as responses to Question 12 demonstrated. This finding reveals that online language learning platforms are believed to be very effective in helping people learn from scratch a foreign language and emphasizes the fact that the use of these particular online platforms is not just for basic learning, but also for reaching a proficient level.

The respondents were asked how the platform was helping them to learn a specific language. The majority of the respondents claimed that the time management (autonomy) and the flexible learning experience was what stimulated them to learn online. Moreover, the second preferred answer was related to the listening to the correct pronunciation of the words, fact that makes the platform capable enough to respect the imposed pronunciation rules.

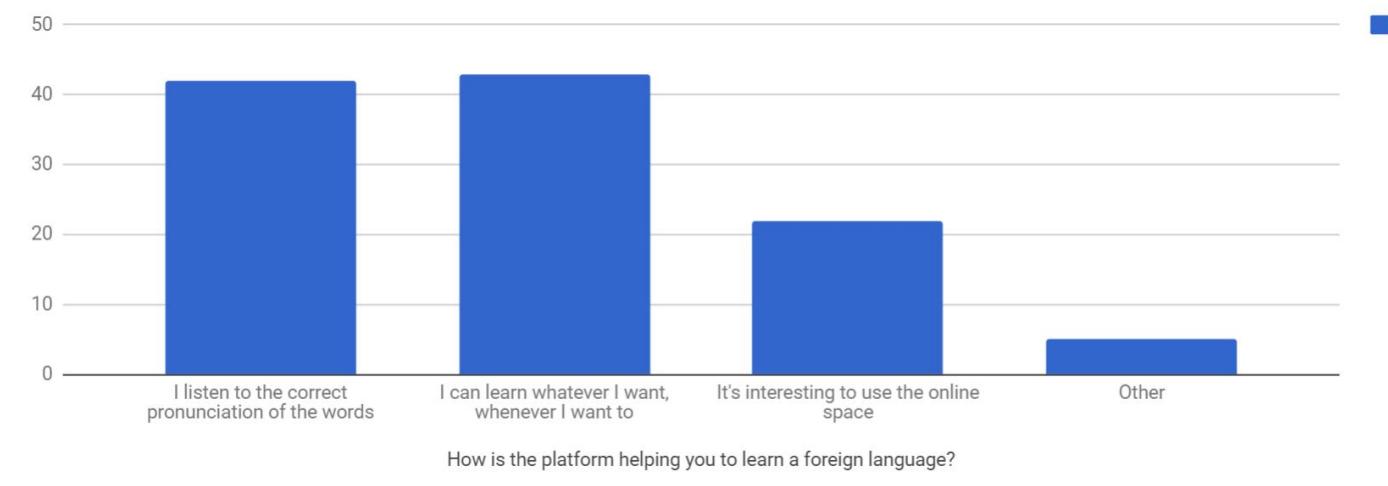

Fig. 3 Students' reasons to learn foreign languages online

The most popular languages among the respondents who preferred learning online were German, English, Spanish and French. However, a large part of the respondents also chose to learn languages like Russian, Portuguese, Dutch, Turkish, Swedish and Japanese. This result indicates that although the learners select to acquire or to develop their knowledge of more common languages, they also opt for learning more difficult ones through online platforms.

The next question (Question 15) aimed to identify the reason for which the respondents wanted to start learning or improving the languages with the help of online instruments. The results emphasize the fact that the main reason for which students chose to learn a language through online methods is motivated by the fact that they prefer to have a flexible schedule, which is also supported by the responses to the previously mentioned questions.

With regard to the allotted learning time, most of the respondents spent 1-2 hours per week for the online language learning process.

The next question concerns the level the students reached in learning the foreign language with the help of the online platform. $\mathrm{A}_{2}{ }^{1}$ was the level that the majority have reached, but 13 respondents out of 60 managed to reach an advanced to expert level.

\footnotetext{
${ }^{1}$ We are using the levels of language proficiency stated in the Common European Framework of Reference for Languages (CEFR).
} 


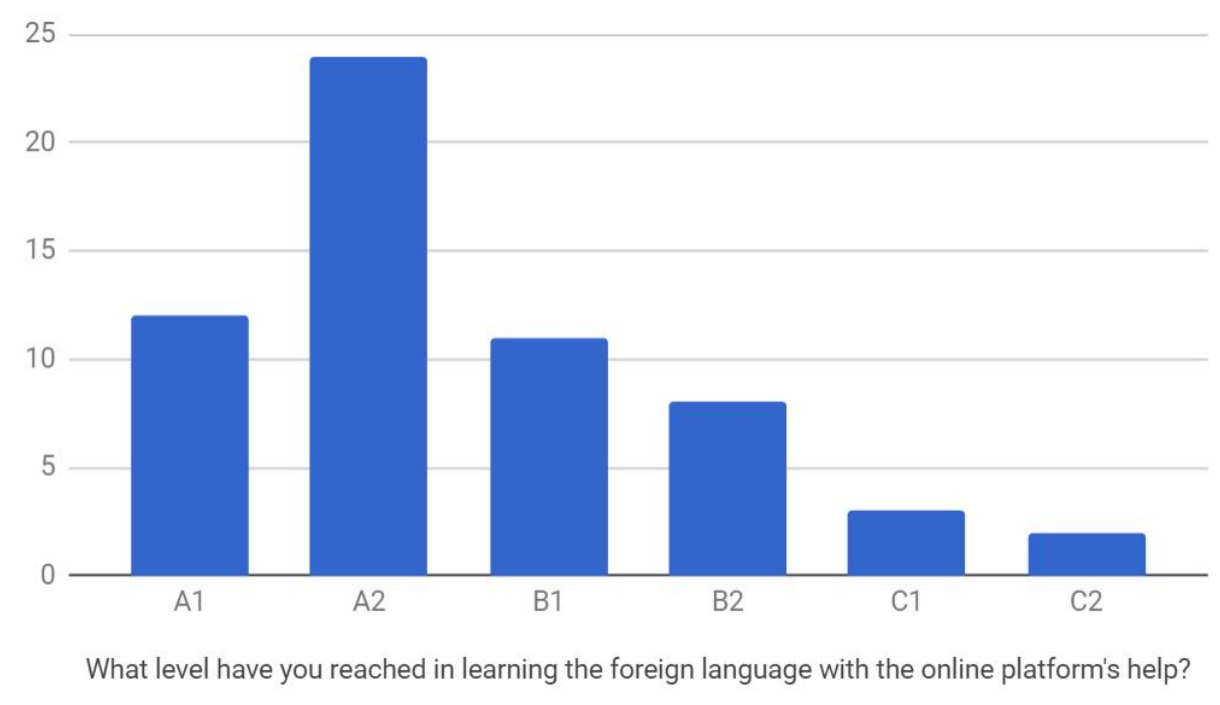

Fig. 4. Students' proficiency levels reached in online foreign language learning

The last question concerned the degree of satisfaction that learners have had after using the online language learning platform. The majority of them responded on a scale from 1 to 5 the levels 3, 4 and 5. A possible interpretation of this result is that it is possible to learn languages through online language learning platforms provided the learners be involved in the learning process and if they are self-motivated enough.

\section{Conclusions}

\subsection{Research validity and data analysis conclusions}

The aim of this research was to investigate if in the $21^{\text {st }}$ century young Romanian adults are inclined to improve their foreign language skills by accessing virtual learning platforms.

Prior studies conducted at the Bucharest University of Economic Studies (Marinescu 2010; David \& Grosu 2013; Grosu-Rădulescu \& David 2015; David \& Grosu-Rădulescu 2016) have also taken into consideration the development of online learning platforms and drew conclusions related to the blended learning platform developed by the university in what concerns learner's educational benefits, the way students perceive the blended learning platform and other learning means. Some of the mentioned studies also focus on how the foreign language teachers' roles have had to adapt to new teaching/learning media.

In 2016, David and Grosu-Rădulescu showed that second language motivation appears to be still relying on face-to-face interaction mediated by teachers. However, one year later ${ }^{2}$ we noticed a change in learner's attitudes and learning methods, the virtual language learning platforms having gained more terrain. As technology is rapidly advancing and changing so are people's perspectives concerning online learning. For that reason, it appears that second language learning motivation is not relying only on face-to-face interaction, but also on the permanent feedback the virtual platform can provide.

\footnotetext{
${ }^{2}$ The present research data gathering took place in November 2017.
} 
Collins' and Munoz's concern with teachers becoming obsolete (2016, p. 133) seems to be supported by the Romanian reality. The progress in technology and e-learning is greater and methods are fast-changing; at the same time students' needs are constantly evolving and they are now starting to prefer learning using online means, platforms, making their learning paths easier. We believe that teaching will still take place in classrooms, but professors will have to integrate more and more online teaching methods in order to keep the learners' attention and motivation alive.

When learning online, motivation comes from the rewarding system that the virtual environment is offering, but also from the sense of being part of the online community. When learning in classrooms, motivation is given by the community of peers and the promise of rewards in the shape of marks. From this perspective it is apparent that the two methods are very similar with the caveat of online learning favouring virtual socializing to the detriment of face-to-face interaction.

To conclude, we believe that our initial assumption was supported by the gathered data, namely that Romanian young adults are inclined to improve their foreign language skills by accessing virtual learning platforms. Learners identify as their main motivation the time flexibility that the online environment offers and the technical advancements which are attractive and appealing on their own. This conclusion appears to be in line with what Reinders \& White were announcing in 2011: "[...] the new understanding of learner autonomy as a set of "specific abilities to navigate different (learning) environments" (Reinders \& White, 2011, p. 2 qtd. in Collins \& Munoz 2016, p.140).

The key findings of our analysis point out that learners do not use the Internet resources to full potential when learning foreign languages, but that there is a significant rise in using virtual learning means. Secondly, results show that Duolingo is the best known online platform preferred by Romanian respondents. Learners choose to learn foreign languages via online platforms because of the time autonomy they enjoy. The satisfaction rate of the users is good to excellent, and the effectiveness of the online language learning platforms (especially Duolingo) was validated, as well.

Related to future research paths, we suggest that further studies be conducted in the direction of the efficiency of other online learning platforms, so as to validate the findings to a larger scale. In addition, future research in the same direction can concentrate on a larger number of learners with more diverse profiles.

\section{2. The limits of our study}

Even if our assumption was substantiated, we are aware that this research has had its limitations. First of all, most of the respondents of this study are members of student organizations, so the responses may not highlight the actual position and perception of a majority of young people in Romania regarding the e-learning platforms. Secondly, we cannot generalize the findings for all the students in Romania because the segment of respondents is fairly narrow (101 respondents). Further country-wide studies might provide a more inclusive view. 


\section{References}

Bauerlein, M. (2009). The dumbest generation: How the digital age stupefies young Americans and jeopardizes our future (or, don't trust anyone under 30). New York: Tarcher/Penguin.

Carr, N. G. (2010). The shallows: What the Internet is doing to our brains. New York: W. W. Norton

Chun, D., Smith, B., Kern, R. (2016). Technology in Language Use, Language Teaching, and Language Learning. The Modern Language Journal 100 (Supplement 2016). Pag. 64-80.

Collins, L., Munoz, C. (2016). The Foreign Language Classroom: Current Perspectives and Future Considerations. The Modern Language Journal 100 (Supplement 2016). Pag. 132-147.

David, I., \& Grosu, L. M. (2013). The Challenges of E-Learning for Trainers Involved in Teaching Foreign Languages to Distance Learners. Quality and Efficiency in E-Learning - Proceedings of the $9^{\text {th }}$ International Scientific Conference "eLearning and Software for Education", 3, 209-214.

David, I., Grosu-Rădulescu, L.M. (2016). Motivation Strategies in Foreign Language Teaching/ Learning - A Comparison of Stimulating Factors in Face-to-Face vs. Online Study. eLearning Vision 2020! Proceedings of the 12th International Scientific Conference "eLearning and Software for Education" Bucharest, April 21 - 22, 2016. Vol. 3. 150-157.

Firth, A., Wagner, J. (1997). On discourse, communication, and (some) fundamental concepts in SLA research. Modern Language Journal 81. 285-300.

Grosu-Rădulescu, L.M., David, I. (2015). Business Communication in English: The Appeal and The Hardships. Rethinking education by leveranging the eLearning pillar of the Digital Agenda for Europe, Volume 3, ed. Ion Ronceanu, Editura Universitatii Nationale de Aparare" Carol I. Proceedings of the 11th International Conference eLearning and Software for Education, Bucharest April 23-24, 2015. 438439 .

Marinescu, R. E. (2010). Teachers' Role in Foreign Languages and Business Communication. Education and Life-Long Learning in the Knowledge-Based Society, Proceedings of the International Conference "Languages as a Lifeskill - New Perspectives on LSP Teaching and Learning" (on CD), 6o9-619.

Reinders, H., \& White, C. (2011). Special issue commentary: Learner autonomy and new learning environments. Language Learning \& Technology, 15, 1-3.

Toth, P. D., Davin, K. J. (2016). The Sociocognitive Imperative of L2 Pedagogy. The Modern Language Journal 100 (Supplement 2016). 148-168.

Trilling, B., \& Fadel, C. (2009). 21st century skills: Learning for life in our times. San Francisco, CA: JosseyBass.

\section{Appendix}

E-questionnaire regarding e-learning foreign languages

1. University:

- Bucharest University of Economic Studies

- University of Bucharest

- University Politehnica of Bucharest

- Other

2. Faculty: (filled out by respondents)

3. Study programs 

a. Bachelor
b. Master

4. Academic year
a. I
b. II
c. III

5. Sex
a. Male
b. Female

6. City/county of origin: (filled out by respondents)

7. Which foreign languages have you studied until now?
a. English
b. French
c. German
d. Italian
e. Japanese
f. Chinese
g. Russian
h. Arabic
i. Turkish
j. Other

8. Are you aware of the existence of the "Blended Learning" online platform, offered as a study support by the Bucharest University of Economic Studies?
a. Yes
b. No

9. Have you ever used online platforms like Duolingo, Babbel and others which help with learning foreign languages?
a. Yes
b. No

10. Which online teaching platforms have you used so far?
a. Duolingo
b. Linguotica
c. Babbel
d. Memrise
e. Other

11. Have you found this platform easy to use? 

a. Yes
b. No

12. For what kind of purposes did you use the platform?

a. Deepening the knowledge of the foreign language

b. Learning a foreign language from zero

13. How is the platform helping you learn a foreign language?
a. I listen to the correct pronunciation of the words
b. I can learn whatever I want whenever I want to
c. It's interesting to use the online space
d. Other

14. What foreign language did you choose to learn/improve the knowledge of with the help of the online platforms?

15. What's the reason for choosing to learn/ improve the knowledge of this foreign language online?
a. I am able to allot it the period of time that I consider suitable
b. The platform offers the opportunity to learn this language at a professional level
c. I feel more comfortable learning on my own

16. How much time did you allot weekly in learning a foreign language through the online platform?
a. 1-2 hours
b. 2-4 hours
c. 4-6 hours
d. $>6$ hours

17. What level have you reached in learning the foreign language with the online platform's help?
a. $A_{1}$
b. $\mathrm{A}_{2}$
c. B1
d. B2
e. $\mathrm{C}_{1}$
f. $\mathrm{C}_{2}$

18. On a scale from 1 to 5 , how much did the online platform help in the foreign language learning process? 
Lucia-Mihaela Grosu-Rădulescu is an Associate Professor with the Department of Modern Languages and Business Communication, the Bucharest University of Economic Studies. She has a $\mathrm{PhD}$ degree in Philology from the University of Bucharest for research in the field of Canadian female ethnic writers. She authored three books and many of her academic articles have been published in Romania and abroad. Her research interests range from foreign language teaching to socio-economy, social psychology and literary and cultural studies. Since 2009 she has been an active member of the Central European Association for Canadian Studies.

Veronica-Maria Stan is a second year Master student with the Faculty of Management of The Bucharest University of Economic Studies. She has a BA degree in Applied Modern Languages, Faculty of International Business and Economics, the Bucharest University of Economic Studies. Her previous work focuses on analyzing e-learning and blended learning methods specifically confined to foreign languages. 